\title{
The Effects of Glosses on Incidental Vocabulary Acquisition in Reading
}

\author{
Xiaohui Xu \\ School of Foreign Languages, Qingdao University of Science and Technology, Qingdao, China \\ Email:xxhqust@tom.com
}

\begin{abstract}
The study has been intended to find out the question of how the three different types of glossing, i.e. glossing in both Chinese and English, glossing in Chinese, glossing in English, exert effects on the incidental vocabulary acquisition through reading. Two testing sections are involved in this study, including the immediate retention testing section and the delayed retention testing section. Based on this finding, implications for the field of foreign language teaching and suggestions have been put forward.
\end{abstract}

Index Terms - type of glossing, incidental vocabulary knowledge, vocabulary acquisition

\section{INTRODUCTION}

\section{A. Importance of Vocabulary Learning}

Vocabulary learning is essential for the learning of a second language, which constitutes a great challenge and enormous task for both second language learners and teachers. As Wilkins (1974) puts that without grammar very little can be conveyed, but without vocabulary nothing can be conveyed. According to Hatch (1983), "basic communicative competence is largely concerned with the strategies the learners use to solicit the vocabulary they need in order to get meaning across". Therefore, lots of studies have been done on second language vocabulary acquisition.

\section{B. Theoretical Significance of the Research}

Many researches have been done on the effects of glosses on incidental vocabulary acquisition. They have mainly on the following issues: what kind of language the glosses shall be in; where the glosses shall be put; and what kind of the glosses shall be in (i.e. multiple choice glosses, monomial glosses, or no glosses).

This research will not only analyze different forms of the glosses, but also give a more detailed description of the influence of glosses on second vocabulary acquisition. It can provide a better explanation for the influence of glosses on incidental vocabulary acquisition. In addition, researches in this field are very few in China, so it can become a reference for Chinese researchers to do further studies.

\section{THEORY}

\section{A. Definition of Incidental Vocabulary Acquisition}

The fact that incidental acquisition takes place in U learning is generally acknowledged researchers. "Most scholars agree that except for the first few thousand most common words, L2 vocabulary is predominately incidentally" (Huckin \& Coady, 1999) Then what is incidental vocabulary acquisition?

The earliest experiment on incidental vocabulary acquisition was done by Gibson (1985). He designed a strip story experiment to study learning vocabulary through speaking, but he didn't give a definition of IVA. Nagy, Herman \& Anderson (1985) bring forward the concept of incidental vocabulary acquisition on the basis of studying how school children acquire their mother tongue. They believe that incidental learning from context accounts for a substantial proportion of the vocabulary growth that occurs during the school years. Long (1981) and Krashen (1985) propose Interactive Hypothesis and Input Hypothesis respectively, but they didn't define incidental vocabulary acquisition. Krashen (1989) argues that language learners could acquire vocabulary and spelling most efficiently by receiving comprehensible input while reading. He intends to use his Input Hypothesis to explain such an unconscious learning process, and describes this process as similar to incidental acquisition.

Schmidt (1994) says that the vocabulary learning refers to the learning without an intent to learn, or as the learning of one thing, e.g. vocabulary, when the learner's primary objective is to do something else, to communicate. Nation (1998) points out that incidental vocabulary acquisition means learners could acquire vocabulary by paying their attention to other things, especially information carried on by the language, and not to learn vocabulary technically. Joe (1998) also mentions that incidental/indirect vocabulary acquisition indicates that learners paid their attention to the comprehension of the context, not the vocabulary in the course of their learning. And it is very effective to acquire vocabulary. Hucky and Coady (1999) define incidental vocabulary acquisition as a learning process of guessing words in reading, and it is a by-product of cognitive activity.

Paribakht \& Wesche (1999) regard incidental vocabulary acquisition as the learning process happens when learners 
try to understand the new words they have heard or read in context. Learners could acquire vocabulary when focusing on something else unrelated to vocabulary learning. Laufer and Hill (2000) define it as the by-product of other activity, such as reading or communication without the learner's conscious intention to learn the words. However they pointed out that even though this kind of learning is incidental or unintentional, it is not unattended, that is, the students are not purposely trying to learn the vocabulary but their attention is called to the words they do not know.

Laufer (2001) point out that incidental vocabulary learning should be defined in contrast to intentional learning. Intentional vocabulary acquisition refers to an activity aiming at committing lexical information to memory. Incidental vocabulary acquisition means that learners acquire the vocabulary incidentally when they are carrying through other learning tasks, e.g. reading articles, listening to English songs. According to Laufer (2003), incidental vocabulary acquisition can be defined as the acquisition of vocabulary as a by-product of any activity not explicitly geared to lexical acquisition. Incidental learning does not mean that the learners do not attend to the words during the task. They may attend to the words (for example, using them in sentences, or looking them up in the dictionary), but they do not deliberately try to commit these words to memory.

Although many researchers have defined incidental vocabulary acquisition from different aspects, there is not an all-sided and authoritative definition of IVA. In this paper, the researcher will adopt the definition made by Laufer (2003) that incidental vocabulary acquisition refers to the acquisition of vocabulary as a by-product of any activity not explicitly geared to lexical acquisition. Few researchers have studied the relationship only between listening and incidental vocabulary acquisition, because generally listening and speaking cannot be separated. Elley (1989) designed two experiments to testify his assumption that young children can learn new vocabulary incidentally from illustrated storybooks read to them. The results show that oral story reading constitutes a significant source of vocabulary acquisition, whether or not the reading is accompanied by teacher explanation of word meanings. Duppy (1993) find that visual and listening can facilitate incidental vocabulary acquisition. After watching Eve minutes' segment of a new movie, the subjects did a vocabulary test.

\section{B. Researches on the Effects of Glosses on Incidental Vocabulary Acquisition}

In this study, the term refers to the supply of vocabulary meanings. Providing vocabulary glosses may be an effective way to help L2 learners to understand new words in a specific context. There are several reasons to use glosses in aiding learning. First, they help readers understand new words more accurately, considering the fact that deriving meaning from context is difficult and risky in some aspects (e.g., Stein, 1993; Hulstijn, 1992). Second, frequent input, looking at the words in the glosses and in the context, can help to retain the meaning in the memory longer (Watanabe, 1992). Students prefer to have glosses in their second/foreign language reading materials (e.g., Jacobs \& Dufon, 1990). Studies with regard to glossing mostly focused on the effects of glossing on second language vocabulary learning and second language text comprehension. This review will discuss text-based and computerized studies respectively.

\section{RESEARCH AND DISCUSSION}

\section{A. Research Questions of the Present Study}

The present study has been intended to find the effects of different types of glosses, that is, glossing in Chinese, glossing in English, and glossing in both Chinese and English, on incidental vocabulary acquisition through reading.

The specific research questions are stated as follows:

Q1: Does a better understanding of the reading passage lead to a higher rate of retention of word knowledge?

Q2: Which type of glossing, among glossing in Chinese, glossing in English and glossing in both Chinese and English, is the most effective in enhancing incidental vocabulary acquisition through reading?

\section{B. Research Design}

The subjects are 103 students of Qingdao University of Science and Technology.

There are 774 words in total in this passage and there are 17 new words in addition to the 18 target words. That is to say, the coverage of words is about $97 \%$; which is just between $95 \%$ and $98 \%$. As has been generally accepted, the coverage of $98 \%$ is needed for reading for pleasure, and for basic necessity, $95 \%$ is needed. So the present coverage in the reading passage is just within this range.

\section{Procedure}

Three classes of non-English-major freshmen of the same proficiency in English took part in the present study. All the tests were finished during normal periods of classes. First, subjects were asked to finish a reading comprehension test, which contains ten comprehension questions after a reading passage.

The reading passage contains 18 target words, among which six are glossed in Chinese, six in English and the remaining six in both Chinese and English. After all the subjects had finished the test, papers of this comprehension test were collected. Then the test of the knowledge of the target words was carried out. A week later, a delayed test was given of the new words.

\section{DISCUSSION}




\section{A. Effects of Glossing on the Word Knowledge in Immediate Retention}

The following table (Table 1) presents us the results of three different types of glossing in immediate test.

TABLE 1

DESCRIPTIVE STATISTICS OF IMMEDIATE TEST

\begin{tabular}{|c|c|c|c|c|}
\hline & $\mathrm{N}$ & Mean & Min. & Max. \\
\hline $\mathrm{CE}$ & 6 & .406 & .00 & 1.00 \\
\hline $\mathrm{E}$ & 6 & .389 & .00 & 1.00 \\
\hline $\mathrm{C}$ & 6 & .531 & .00 & 1.00 \\
\hline
\end{tabular}

Since it is more convenient to demonstrate the results of the test, averages are used again in this part. For each item, the full score is one point. As could be concluded from the table above, the mean of the scores in glossing in Chinese (0.531) is the highest among the three types and the means of the scores (i.e. 0.406 and 0.389 respectively) in other two types are very close to each other. On the other hand, the standard deviations of the three tests are close to one another, which shows that students did not differ much in the performance within each of the three types of glossing.

The reason why the type of glossing in both Chinese and English (CE) failed to achieve the highest retention rate of word knowledge may be due to various reasons. First of all, as has been testified by the data from the interview with students after the first testing, on encountering this type of glossing, some students did not read carefully or even just ignored the English definition.

Generally, English definitions are much longer than Chinese definitions, or their Chinese "equivalents," more exactly. As a consequence, students were in such a hurry to finish the reading task that they may just scan the Chinese definition following its English counterpart quickly and carelessly. This is in line with what we have discovered in literature review.

On the other hand, glossing in mother tongue is easy to understand and convenient to remember for most of the subjects. Another possible reason might be that without the long English definition preceding the short. Chinese definition, subjects may have a lower degree of anxiety while reading the gloss.

Glossing in English (E) is the least effective one. For one thing, just as has been mentioned above, English definition is usually much longer than its Chinese counterpart. This is harder for subjects to understand and even more difficult to commit to memory. For another, this might increase the degree of anxiety of students, thus producing a "vicious circle".

In a word, in the test of immediate retention of incidental vocabulary acquisition, glossing in Chinese (C) is the most effective, and glossing in both Chinese and English (CE) is the second most effective, and the poorest is glossing in English (E).

\section{B. Effects of Glossing on the Word Knowledge in Delayed Retention}

Table 2 in the below demonstrates the results of the second test of word knowledge.

TABLE 2

DESCRIPTIVE STATISTICS OF DELAYED TEST

\begin{tabular}{|c|c|c|c|c|}
\hline & $\mathrm{N}$ & Mean & Min. & Max. \\
\hline $\mathrm{CE}$ & 6 & .268 & .00 & .83 \\
\hline $\mathrm{E}$ & 6 & .233 & .00 & .83 \\
\hline $\mathrm{C}$ & 6 & .253 & .00 & .83 \\
\hline & Notes: CE = (average of items Glossed in) Chinese and English \\
& E $=$ (average of items Glossed in) English \\
& $\mathrm{C}=$ (average of items Glossed in) Chinese
\end{tabular}

From Table 2, it could be seen that different from what has been found in the immediate test, the mean of the scores for the words glossed in both Chinese and English (CE) is the highest among the three. The type of glossing solely in Chinese (E) has dropped to the second place. And the same as the results in the immediate testing, glossing in English (E) is the last one in the three.

In other words, there is no significant difference among the three types of glossing in the delayed test of the word knowledge.

\section{CONCLUSION AND SUGGESTION}

\section{A. Conclusion}

In conclusion, the major findings of the present study are stated as follows:

1) A better comprehension of the text does lead to a higher rate of incidental vocabulary acquisition of word knowledge.

2) Glossing in both Chinese and English (CE) is the most effective in enhancing the word knowledge in both the immediate retention and in the delayed retention. 
3) Glossing in Chinese (C) is the most effective in the immediate retention test of word knowledge. But this type is the least effective in enhancing the word knowledge in the delayed retention.

4) Glossing in English (E) the poorest in enhancing the word knowledge in the immediate retention.

\section{B. Suggestion}

Accordingly, in the future studies, more subjects should be included in the experiment to improve the generalization of the conclusion. In addition, subjects of different proficiency, including college students of different grades, junior and senior high school English learners, between the testing sections may be included. Last but not least, the time span should be lengthened to thoroughly long-term the present effects of different types of treatments.

\section{REFERENCES}

[1] Elley, W. (1989). Vocabulary Acquisition from Listening to Stories. Reading Research Quarterly, 19.

[2] Elley, WB. (1991). Acquiring literacy in a second language: the effect of book-based programs. Language Learning, 41(3).

[3] Ellis, R. (1999). Second Language Acquisition. Shanghai: Shanghai Foreign Language Education Press.

[4] Hulstijn, J. (1992). Retention of Inferred and Given Word Meanings: Experiments in Incidental Vocabulary Learning. In P. Arnaud \& H. Bejoint (eds.). Vocabulary and Applied Linguistics. London: Macmillan.

[5] Hulstijn, J and B Laufer. (2001). Some empirical evidence for the involvement load hypothesis in vocabulary acquisition. Language Learning, 3.

[6] Hulstijn, JH, M Hollander and T Greidanus. (1996). Incidental Vocabulary Learning by Advanced Foreign Language Students: the Influence of Marginal Glosses, Dictionary Use and the Reoccurrence of Unknown Words. The Modern Language Journal, 80.

[7] Iaufer, B. (2001). Reading, Word-focused Activities and Incidental Vocabulary Acquisition in a Second Language. Prospect, 16(3).

[8] Laufer, B and J Hulstijn. (2001). Incidental Vocabulary Acquisition in a Second Language: the Construct of Task Induced Involvement. Applied Linguistics, 22(1).

[9] Pulido, D. (2004). The Relationship between Text Comprehension and Second Language Incidental Vocabulary Acquisition: A Matter of Topic Familiarity? Language Learning, 54(3).

Xiaohui Xu was born in Zibo, China in 1977. She received her M.A. degree in Foreign Linguistics and Applied Linguistics from Ocean University of China in 2010.

She is currently a lecturer in the School of Foreign Languages, Qingdao University of Science and Technology, Qingdao, China. Her research interests include Second Language Acquisition and Foreign Language Teaching. 